\title{
A gross anatomical study of the styloid process of the temporal bone in Japanese cadavers
}

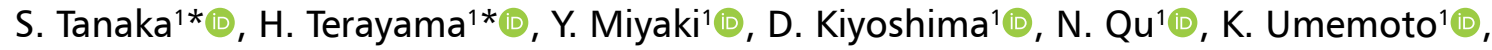

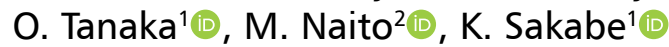 \\ ${ }^{1}$ Department of Anatomy, Division of Basic Medical Science, Tokai University School of Medicine, Kanagawa, Japan \\ 2Department of Anatomy, Aichi Medical University, Aichi, Japan
}

[Received: 8 December 2020; Accepted: 17 January 2021; Early publication date: 23 February 2021]

Background: The incidence of an elongated styloid process (SP) and average length and diameter of SP have not been reported using Japanese cadavers. Data on the female-to-male ratio of an elongated SP vary. We calculated the average length and diameter of SP in Japanese cadavers and compared SP lengths between sexes.

Materials and methods: Twenty-seven sides (right and left of bodies) in males and 51 sides in females were analysed. Measurements were obtained from the inferior external acoustic meatus to the distal tip of the SP. SP diameters at the proximal base, midpoint, and distal tip were measured. $S P>30 \mathrm{~mm}$ was considered elongated. We used Welch's t-test for the statistical analysis. Fisher's exact two-tailed test was also performed to analyse the female-to-male elongation ratio. A p-value $<0.05$ was considered statistically significant.

Results: Styloid process elongation prevalence was $29.5 \%$ in our sample. The average full length was $27.04 \pm 7.88 \mathrm{~mm}$ overall; the average diameters were $5.41 \pm 1.77 \mathrm{~mm}$ at the proximal base and $2.21 \pm 1.22 \mathrm{~mm}$ at the distal tip. The average SP measurement was $26.81 \pm 5.92 \mathrm{~mm}$ in males and $27.16 \pm$ $\pm 8.79 \mathrm{~mm}$ in females $(p=0.74)$. The female-to-male ratio of SP elongation was $1: 2(p=0.041)$. Females had longer full lengths of non-elongated SPs than males $(p=0.004)$. Males had wider diameters at the proximal base of elongated SPs than females $(p=0.017)$.

Conclusions: The average length of SP was $27.04 \mathrm{~mm}$ in the Japanese population and about $30 \%$ of the Japanese presented $S P \geq 30 \mathrm{~mm}$. Male had significantly higher rate than female among the $S P \geq 30 \mathrm{~mm}$, and female had significantly longer SPs than male among the $S P<30 \mathrm{~mm}$. Anatomically, the $S P$ gets narrow as distally goes. Our anatomical findings would be beneficial to creating treatment plans, diagnosis, and surgery. (Folia Morphol 2022; 81, 2: 493-502)

Key words: Eagle syndrome, elongation, styloid process, cadaver, second branchial arch

Address for correspondence: Dr. H. Terayama, Department of Anatomy, Division of Basic Medical Science, Tokai University School of Medicine, 143 Shimokasuya, Isehara-shi, Kanagawa 259-1193, Japan, tel: +81-463-931121 (ext: 2513), e-mail: terahaya@tokai-u.jp

*S. Tanaka and H. Terayama contributed equally to this work.

This article is available in open access under Creative Common Attribution-Non-Commercial-No Derivatives 4.0 International (CC BY-NC-ND 4.0) license, allowing to download articles and share them with others as long as they credit the authors and the publisher, but without permission to change them in any way or use them commercially. 


\section{INTRODUCTION}

The styloid process (SP) is a slender bony structure projecting out downwardly from the temporal bone and lying anterior to the stylomastoid foramen $[3,25]$. The average normal length of the SP ranges from $20 \mathrm{~mm}$ to $30 \mathrm{~mm}[18,25,45]$; the SP of $>30 \mathrm{~mm}$ is considered elongated [26, 28, 42]. The distal tip of the SP is usually located posterior to the tonsil fossa [3]. Because external and internal carotid arteries run at the distal aspect of the SP, the SP is clinically significant $[7,38]$. The internal jugular vein also runs posteriorly to the carotid arteries [35]. In addition to these blood vessels, the accessory, vagus, facial, and glossopharyngeal nerves run close to the styloid process [35]. The accessory and vagus nerves pass medially to the SP, and the facial nerve lies anteromedially to it [36]. The glossopharyngeal nerve is the most proximal to the SP and runs from the jugular foramen $[25,35]$.

The symptoms of Eagle's syndrome are associated with styloid process elongation and mineralisation of a part of the stylohyoid ligament [35]. An elongated styloid process results in irritation of cranial nerves and impingement of the circulation at the distal tip $[18,35]$. Vague neck pain is often reported as a primary symptom [37]. Tongue pain, dysphonia, ear pain, dysphagia, odynophagia, vertigo and tinnitus, facial paraesthesia, vocal change, and sore throat (pharyngolaryngeal paraesthesia) could also occur [35]. Clinically, patients who have elongated SP are often asymptomatic [32], and only $4 \%$ of the patients with elongated SP present symptoms [7]. Symptomatic patients were usually over 40 years old [3], and females are twice likely to present symptoms [2]. Another study indicated that 12 females and 9 males with Eagle syndrome had elongated SPs and clinical presentation [46]. Association between SP and sex is important. Patients with SP elongation had headaches (18.7\%) and hypertension (17.1\%) [1]. Clinical signs and symptoms are influenced by not only length but also the location and size of the SP. Nevertheless, studies investigating the average of SP diameter are scarce. While the proximal base thickness was reported to be approximately $4.4 \mathrm{~mm}[24,49]$, the average diameter in the Japanese population has not been investigated.

Most previous studies investigated the length of the SP and incidence of SP elongation $[1-8,10,12-14$, $16,18,19,21,22,25-27,29-31,33,34,39,40,43]$. Eagle (1958) [7] reported that only $4 \%$ of the general population experience Eagle's syndrome. Rogers and Chang (2007) [41] noted that the frequency is "very controversial." Another study found that the prevalence of enlarged SP was higher in females than in males [37].

A few studies on the prevalence of SP elongation in the Japanese population have been conducted, showing that the average SP lengths were $17.4 \mathrm{~mm}$ and $18.8 \pm 5.26 \mathrm{~mm}$, respectively $[29,30]$. These studies evaluated the SP using posteroanterior X-ray and panoramic radiographs; however, none of the studies performed measurements in a Japanese population. Only two cadaver studies $[3,25]$ and three skulls studies $[3,31,39]$ were done to determine the prevalence of elongated SP. In cadaver studies, 80 SPs were measured and 22 cadavers were examined by Moffat et al. [25] and Balcioglu et al. [3], respectively. In skull studies, 232 skulls, 41 SPs, and 262 SPs were evaluated $[3,31,39]$. Few studies on cadavers have been reported.

Therefore, this study aimed: 1 ) to examine the average length and diameter of the $S P, 2$ ) to determine the prevalence of elongated SP in a Japanese population, and 3) to compare the SP lengths between sexes.

\section{MATERIALS AND METHODS}

Of the 92 sides of the cadavers included in this study, only 78 ( 27 sides in males and 51 sides in females) were analysed. The cadavers were fixated using formaldehyde. Broken SPs were excluded and all other SPs were included. Gross dissections were performed in the dissection room. This study was approved by the Institutional Review Board for Clinical Research, Tokai University (No. 17R-310).

We dissected the epidermis to remove the subcutaneous tissues. The sternocleidomastoids, parotid salivary gland, and masticatory muscles were removed. Subsequently, we broke the mandible, and the medial and lateral pterygoid muscles were removed to expose the SP and the styloglossus, stylohyoid, and stylopharyngeus muscles.

Measurements were performed from the inferior part of the external acoustic meatus to the distal tip of the SP, according to a previous study [31]. Figure 1 shows the SP dissection. In our study, a string and a pair of tweezers were directly used for the measurement of SP length. Thereafter, a ruler and a calliper were used to measure diameter. Diameters of the proximal base (Fig. 1/1/), mid-point (Fig. $1 / 2 /)$, and distal tip (Fig. $1 / 3 /$ ) were measured. The mid-point 


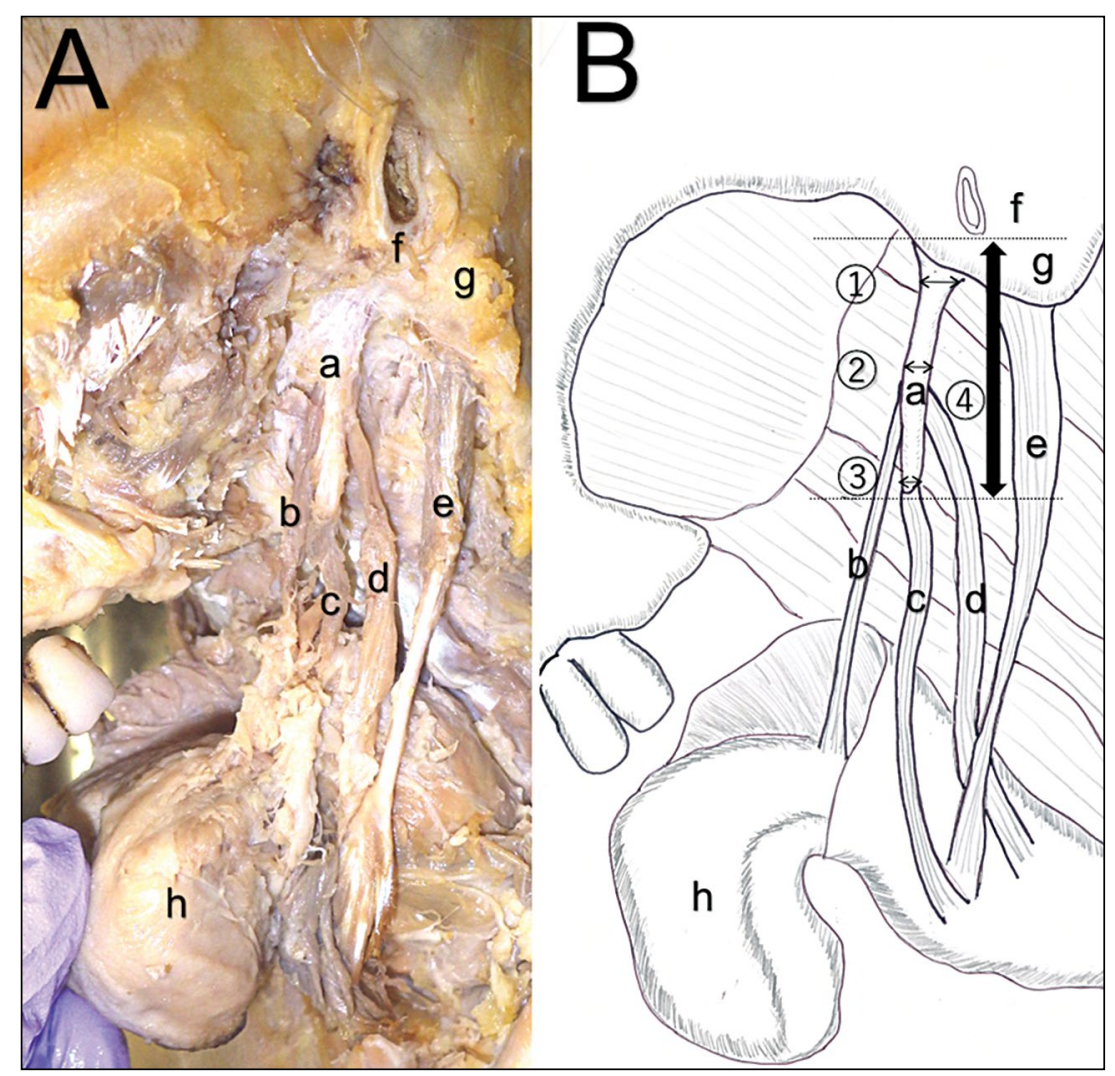

Figure 1. Styloid process from dissection (A) and a schema of the left inferolateral view (B); a - styloid process; $b$ - styloglossus muscle; $\mathrm{c}$ - stylohyoid muscle; $d$ - stylopharyngeus muscle; $\mathrm{e}$ - digastric muscle; $f$ - external acoustic meatus; $g$ - mastoid process; $h$ tongue. The length and width were measured $(\mathbf{B}) ; 1$ - the proximal base; 2 - the mid-point; 3 - the distal tip (the horizontal double-headed arrows); 4 - length (the vertical double-headed arrow) from the external acoustic meatus (the upper dotted line) to the styloid process (the lower dotted line).

diameter was measured at the middle of the full length of the SP. Moreover, length was measured from the inferior part of the external acoustic meatus to the distal tip of the styloid process (Fig. $1 / 4 /$ ). Based on previous studies [6, 19, 23], an $\mathrm{SP} \geq 30 \mathrm{~mm}$ is considered elongated. Previous reports on the SP are shown in Table 1. This study had a limitation, i.e. the medical history prior to death was not identified; therefore, any pre-existing symptoms were unknown.

As shown in Table 2, the SP measurements were divided into three categories: all, $>30 \mathrm{~mm}$, and $<30 \mathrm{~mm}$. Length and diameter according to sex (male and female) and side (right and left) were compared among the three categories. We compared the differences in the average values. Because the sample sizes differed among the categories, we used Welch's t-test for the statistical analysis. Fisher's exact twotailed test was also performed to analyse the female-to-male elongation ratio. A $p$-value $<0.05$ was considered statistically significant. The analyses were performed using Excel (Microsoft, USA).

\section{RESULTS}

A comparison of the prevalence of elongated SP and the average length of the SP according to previous studies is shown in Table 1. Only two cadaver studies of the SP have been conducted, which were not in Japan (Table 1). In our cadaver study, which included Japanese individuals, the prevalence of SP elongation was $29.5 \%$ (Table 1). Of the 78 SPs, 23 measured $\geq 30 \mathrm{~mm}$. Three cadavers presented bilateral elongation and 17 had unilateral elongation. The longest SP was from an 89-year-old female $(47.0 \mathrm{~mm}$ on the right and $55.0 \mathrm{~mm}$ on the left). In Table 2, a comparison of the characteristics of the SP is shown. The differences in the length of the SP (i.e., > $30 \mathrm{~mm}$ or not) were evaluated according to sex and side of the SP. The average length was $27.04 \pm 7.88 \mathrm{~mm}$ (Tables 1, 2), and the average diameter was $5.41 \pm$ $\pm 1.77 \mathrm{~mm}$ at the proximal base, $3.68 \pm 1.77 \mathrm{~mm}$ at the mid-point, and $2.21 \pm 1.22 \mathrm{~mm}$ at the distal tip (Table 2). Eleven and $12 \mathrm{SPs}>30 \mathrm{~mm}$ were found in females and males, respectively. In females, 


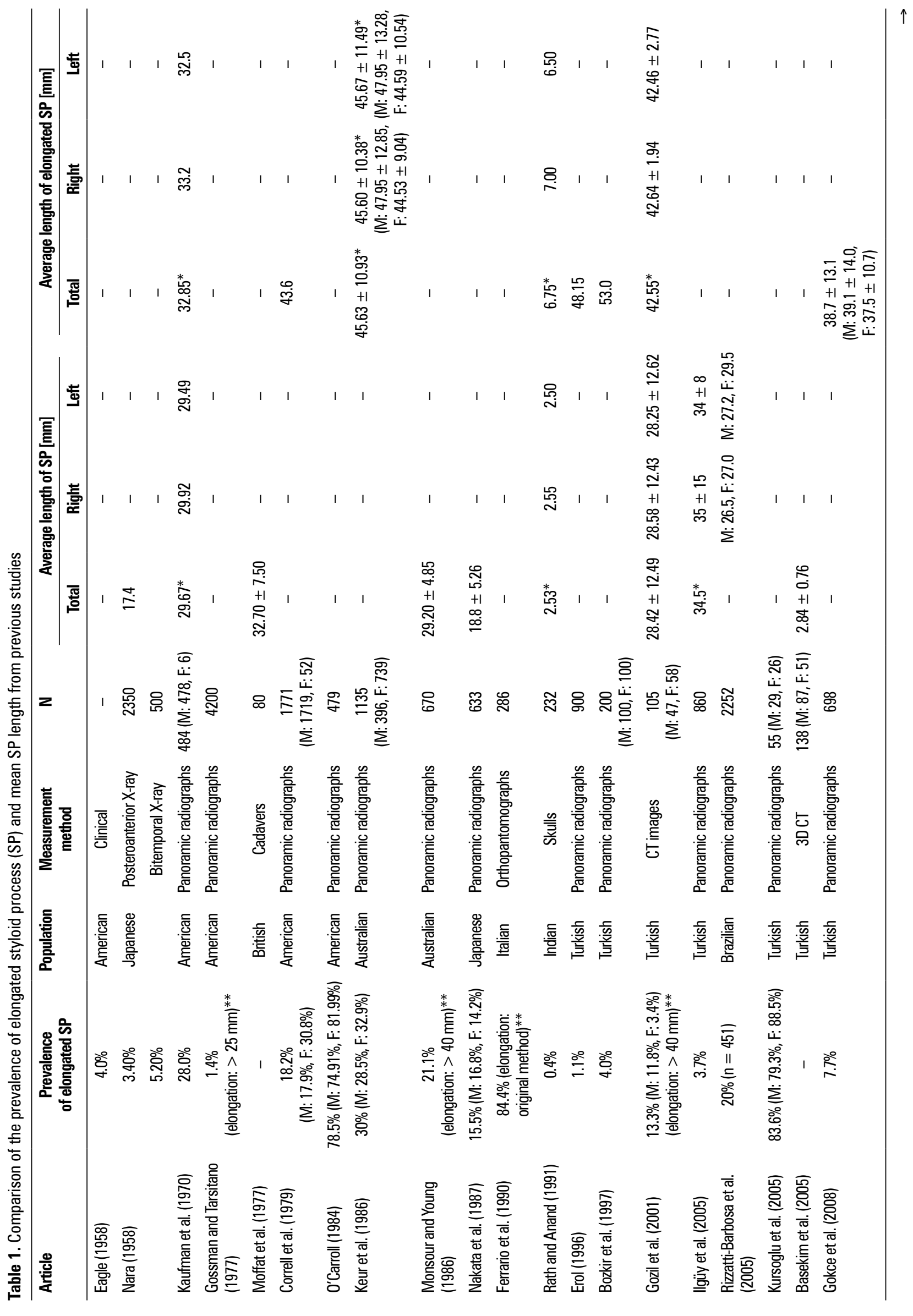




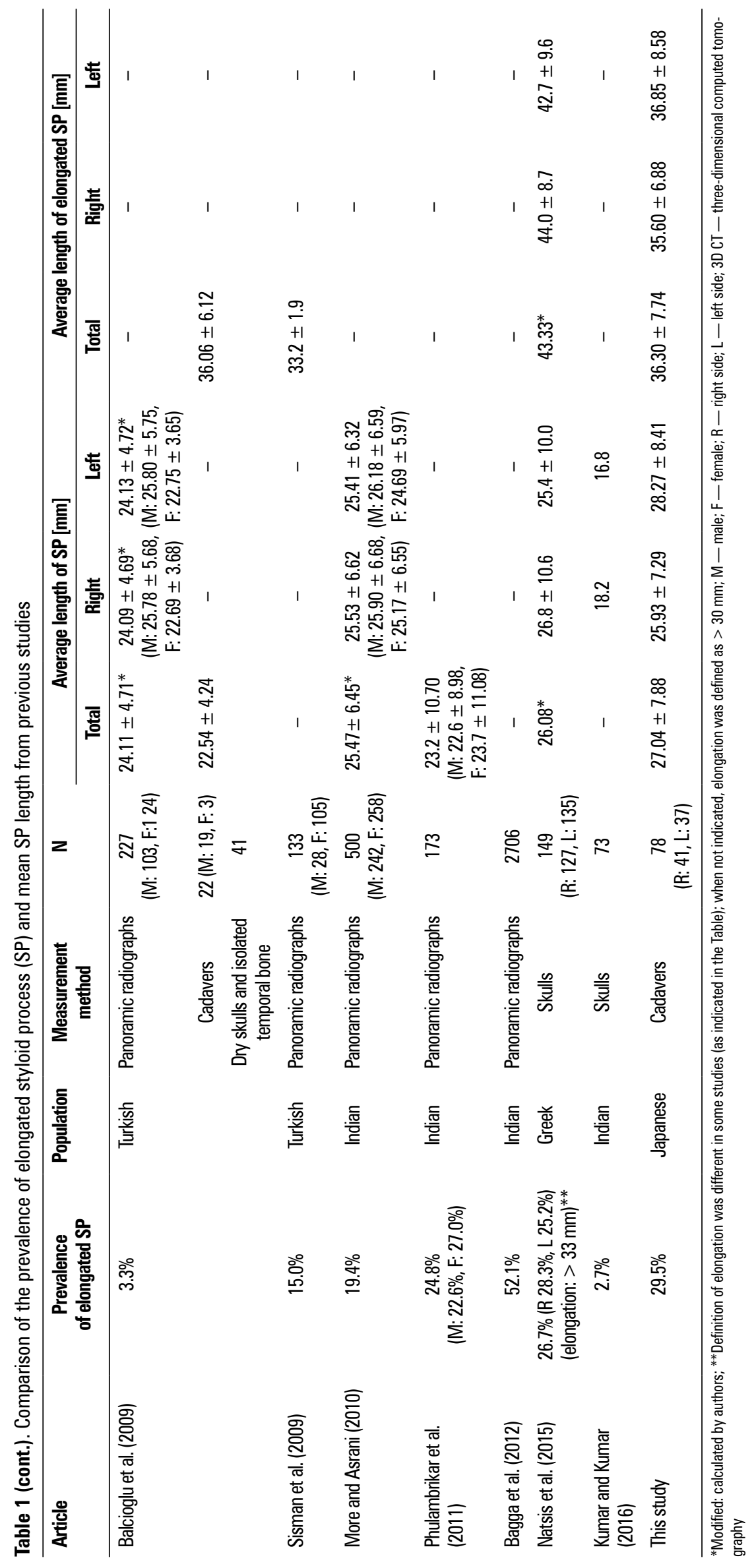







11 elongations were found in 51 SPs (22\%). In males, 12 elongations were found in 27 SPs (44\%). Males had a greater tendency to develop SP elongation, and the female-to-male ratio of SP elongation was 1:2 $(p=0.041)$. Elongation rates were not significantly different between the left and right side $(p=0.33)$. No statistically significant difference in the diameter or length in all cases (left and right) was found (Table 2). Males had a full SP length of $26.81 \pm 5.92 \mathrm{~mm}$, while females had a length of $27.16 \pm 8.79 \mathrm{~mm}$. Significant differences in full length on the non-elongated SP $(p=0.004)$ and in diameter at the proximal base of the elongated SP ( $p=0.017$ ) were noted between sexes. The diameter and length were not significantly different between sexes in other cases (Table 2).

\section{DISCUSSION}

The prevalence of SP elongation was $29.5 \%$ from the 78 sides in our study. The average SP length was $27.04 \pm 7.88 \mathrm{~mm}(27.16 \pm 8.79 \mathrm{~mm}$ in females and $26.81 \pm 5.92 \mathrm{~mm}$ in males). The average diameter at the proximal base on the elongated SP was $5.91 \pm$ $\pm 1.53 \mathrm{~mm}$ (5.92 $\pm 1.56 \mathrm{~mm}$ in males and $5.91 \pm$ $\pm 1.58 \mathrm{~mm}$ in females); a significant difference was noted between sexes. The female-to-male SP elongation ratio was 1:2. Thus, sex may influence SP elongation.

The prevalence of SP elongation varied from $0.4 \%$ to $84.4 \%$ in previous studies (Table 1 ). Rath and Anand (1991) [39] reported that the prevalence of enlarged styloid in their skull study ( $n=232$ ) was $0.4 \%$, whereas X-ray based studies showed prevalences of $4 \%$ [7], 18.2\% [6], and $84.4 \%$ [10]. In our study, we evaluated 78 SPs and found that 23 SPs measured $>30 \mathrm{~mm}$. The prevalence of SP elongation in our study was $29.5 \%$, consistent with the finding of Keur et al. (1986) [19], i.e. 30.0\%. Nara (1958) [30] reported a $3.4 \%$ and $5.2 \%$ rates, and Nakata et al. (1987) [29] reported 15.5\%. However, these studies were performed using $\mathrm{X}$-ray, whereas our study was the first to measure the prevalence in Japanese cadavers.

Balcioglu et al. (2009) [3] showed that the average SP length ranged from 20 and $30 \mathrm{~mm}$; thus, in most studies, $\geq 30 \mathrm{~mm}$ is considered elongation $[3,6,15$, 19], a value we adopted in this study. The method of dry skulls and panoramic radiographs measurement was conducted in several ways. According to Eagle (1958) [7], only $4 \%$ of patients who had elongated SP complained of pain and presented sign and symptoms. The average SP length has been highlighted in previous studies; however, only few studies focused on the diameter. Anatomically, nerves and blood vessels are located closely around the SP; hence, the diameter of the SP is a factor that could influence clinical symptoms. A small diameter may impinge glossopharyngeal, accessory, and vagus nerves and internal/external carotid arteries, and various symptoms and signs could be attributed to the anatomy and location of these vessels and nerves.

Styloid process thickness is also important. A skull study showed that thickness at the proximal base varied from 4.34 to $4.4 \pm 1.2 \mathrm{~mm}$ on the right side and from 4.47 to $4.4 \pm 0.9 \mathrm{~mm}$ on the left side [21, 49]. Margam and Jadhav (2015) [24] demonstrated that at the proximal base males had $4.53-\mathrm{mm}$ thickness on the right and 4.83-mm thickness on left; for females, it was $4.33 \mathrm{~mm}$ and $5.00 \mathrm{~mm}$, respectively. Average thickness at the distal tip for both sexes was $1.5 \pm 0.6 \mathrm{~mm}$ on the right and $1.4 \pm 0.5 \mathrm{~mm}$ on the left [49]. To the best of our knowledge, our study is the first to examine the diameter of the SP in the Japanese population. We found that thickness at the proximal base was $5.41 \pm 1.91 \mathrm{~mm}$ on the right and $5.41 \pm 1.63 \mathrm{~mm}$ on the left, and thickness at the distal tip was $2.33 \pm 1.27 \mathrm{~mm}$ on the right and $2.07 \pm 1.17 \mathrm{~mm}$ on the left (Table 2 ). Regardless of the presence of elongation, SPs tended to narrow distally in most of the cases. Previous studies in the Indian population indicated that increased thickness at the proximal base would compress facial nerves [21, 24]. Therefore, SP thickness is a factor influencing the signs and symptoms. Presenting symptoms depend on the location of the anatomical structure instead of the SP length. Katayama et al. (1989) [17] reported a patient with 71-mm SP on X-ray who showed no symptoms. Nevertheless, it is highly possible that a long and wide SP could compress the carotid artery or nerves. Tsuruta et al. (1985) [48] suggested other possible mechanisms of the symptoms: 1) sympathetic nerves could be stimulated, resulting in dull pain on the area of vascular distribution, 2) glossopharyngeal nerve stimulation results in tinnitus and earache, and 3) a long SP could limit the movement of the hyoid bone, which in turn affects swallowing and speaking. These findings suggest that a combination of length and thickness of the SP and location of the anatomical structure could lead to clinical symptoms and signs.

In our study, the longest SP was found in a female patient who presented bilateral enlarged SPs (47.00 $\mathrm{mm}$ on the right and $55.00 \mathrm{~mm}$ on the left). The 
average length was $27.16 \pm 8.79 \mathrm{~mm}$ in females and $26.81 \pm 5.92 \mathrm{~mm}$ in males; no significant difference was observed. In a previous panoramic radiogram-based Japanese study, the average was $23.1 \pm$ $\pm 7.0 \mathrm{~mm}$ in females and $22.5 \pm 8.1 \mathrm{~mm}$ in males; no significant difference was noted [47]. Takeuchi et al. (1987) [47] reported no significant difference in the average length between sexes in Japan, similar to our study's finding. Although in the Japanese population, females have a longer average length; no statistical significance was noted. However, Balcioglu et al. (2009) [3] showed that males had a longer average SP length than females in the Turkish population, although no statistical significance was found. In our study, females had 11 and males had 12 elongated SPs, and the female-to-male elongation ratio was $1: 2$, a significant difference. Swain et al. (2017) [46] showed a 0.75:1 ratio in the Indian population; however, a significant difference was not reported. On the other hand, its rate was reported differently depending on population as the ratio of 3:1 in the Indian population [37] and 9:1 in Turkish population [3]. These findings suggest that the differences in prevalence of elongation and average SP length between sexes vary by race. Sex is a critical factor for the facial dimension differences as females have smaller bigonial breadth, face length, and face width than males [52]. Based on previous studies, females have shorter facial anthropometric dimensions. In our study, males had a significantly higher rate of elongation than females; this suggests that the size of the face is possibly an influencing factor. According to a study on facial morphological characteristics across various races, both sexes in India are known to have smaller nose height and identical intercanthal width, whereas Japanese males have greater intercanthal width [9]. The average distance between the sides of the SP at the distal tip was $64.4 \mathrm{~mm}$ in the Indian population [21]. Therefore, not only gender but also race or ethnicity contributes to the incidence of Eagle's syndrome. When comparing average lengths, attention must be paid to the anthropometric measurement, which should be investigated in future research on the SP. Moreover, statistical differences in full length on the non-elongated SP and in diameter at the proximal base on the elongated SP were noted between sexes in this study. Such a difference in morphology between sexes can contribute to the field of forensic medicine. In the future, autopsy cases will need to be increased.
The SP originates from Reichert's cartilage, which is from the second brachial arch. Reichert's cartilage consisted of four segments: tympanohyal, stylohyal, ceratohyal, and hypohyal. The tympanohyal is responsible for the formation of the proximal part and stylohyal for the formation of the distal part of the SP. The ceratohyal is responsible for the formation of the stylohyoid ligament and hypohyal for the formation of the lesser horn of the hyoid bone. The ceratohyal of Reichert's cartilage becomes the stylohyoid ligament; however, ossification occurs due to unknown causes [25]. One case report found that extensive bilateral ossification of stylohyoid complex, which lengthen 65 $\mathrm{mm}$ on the right and $62 \mathrm{~mm}$ on left [44]. The cause of ossification could be trauma, bone malformation, or abnormal bone metabolism; the exact details remain unknown [11].

Kaufman et al. (1970) [18] showed that in most cases, patients aged $\geq 40$ years commonly present symptoms. In a Japanese study that considered $>20 \mathrm{~mm}$ as elongation, age between 30 and 50 years accounted for $70 \%$ of the 55 cases with pharyngolaryngeal paraesthesia, and elongation was considered a factor for pharyngolaryngeal paraesthesia; $43.0 \%$ of elongations were found in patients without any symptoms, whereas $74.5 \%$ of elongations were found in those with pharyngolaryngeal paraesthesia [17]. To confirm the diagnosis of pharyngolaryngeal paraesthesia, the following three factors must be observed: SP length $>30 \mathrm{~mm}$ based on imaging test, clinical symptoms, and Eagle's syndrome symptoms that are aggravated by tonsillar pillar palpation exam $[11,15]$.

Natsis et al. (2015) [31] claimed that no gold standard for measuring the length of the SP exists; however, recently, panoramic radiograph has been used to confirm elongation $[2,50]$, as well as three-dimensional computed tomography [20]. Treatment options for enlarged SP include conservative therapy and surgery. Surgery is usually performed after conservative therapy, including steroid injection and non-steroidal anti-inflammatory drugs. Surgical treatment includes extraoral and intraoral approaches. Prior to the SP cut, the fascia and periosteum are dissected to reveal the SP $[15,20,35]$. Thereafter, the styloglossus, stylohyoid, and stylopharyngeus muscles and the SP are removed. The three muscles are removed to prevent the occurrence of dysfunction [51]. Thus, understanding muscle attachments and the anatomical structure surrounding the SP is vital. 


\section{Limitations of the study}

This study has four limitations. First, we were unable to access past medical records; therefore, no information on any symptoms and signs related to elongated SP was obtained. Second, the sample size was limited. Third, clinical symptoms and the nerve pathways around SP were not observed in this study. As a nature of the study, this study was not able to assess any clinical presentation during examined people's lifetime. When patients present any symptoms, it is necessary for clinicians to search nerve anatomical location. Fourth, muscle origins and the characteristics of the styloglossus, stylohyoid, stylopharyngeus muscles were not identified in all cases. During dissection, we found that the three muscles and the stylohyoid ligament arose from different locations. The run of the muscle structure is vague. Therefore, determining the muscle attachments is necessary in the surgical treatment for Eagle syndrome. Muscles need to be cut, and understanding the structure is crucial for surgery. Future studies should examine the variations in the origin of the muscles attached to the SP.

\section{CONCLUSIONS}

This study is the first cadaver study measuring the average SP lengths and diameters in the Japanese population. The prevalence of SP elongation was $29.5 \%$ in the Japanese population. The average length was $27.04 \mathrm{~mm}$ with no difference between sexes among all SPs, but female had significantly longer SPs among the $\mathrm{SP}<30 \mathrm{~mm}$. Elongation is twice as common in males (12 out of 27 sides) as in females (11 out of 51 sides) in the Japanese population. Anatomically, the SP gets narrow as distally goes; the average diameter was $5.41 \mathrm{~mm}$ at the proximal base and $2.21 \mathrm{~mm}$ at the distal tip. Our anatomical findings would be beneficial to creating treatment plans, diagnosis, and surgery.

\section{Acknowledgements}

The authors thank Prof. Tsutomu Sato, Dr. Kaori Suyama, Mr. Noriyuki Kosemura, Ms. Kyoko Endo, and Ms. Yuko Furuya for their excellent secretarial support. We also thank Mr. Taiju Nagai, Mr. Hayata Fukushima, Mr. Kohei Nakanishi, and Mr. Runo Tomita for their assistance in data collection. We would like to thank Editage (www.editage.jp) for the English language editing.

\section{Conflict of interest: None declared}

\section{REFERENCES}

1. Asutay F, Erdem N, Atalay $Y$, et al. Prevalence of elongated styloid process and Eagle syndrome in East Eagean population. Bezmialem Sci. 2019; 7(1): 28-32, doi: 10.14235/ bas.galenos.2018.991.

2. Bagga MB, Kumar CA, Yeluri G. Clinicoradiologic evaluation of styloid process calcification. Imaging Sci Dent. 2012; 42(3): 155-161, doi: 10.5624/isd.2012.42.3.155, indexed in Pubmed: 23071965.

3. Balcioglu HA, Kilic C, Akyol M, et al. Length of the styloid process and anatomical implications for Eagle's syndrome. Folia Morphol. 2009; 68(4): 265-270, indexed in Pubmed: 19950078.

4. Başekim CC, Mutlu H, Güngör A, et al. Evaluation of styloid process by three-dimensional computed tomography. Eur Radiol. 2005; 15(1): 134-139, doi: 10.1007/s00330-0042354-9, indexed in Pubmed: 15221266.

5. Bozkir MG, Boğa H, Dere F. The evaluation of elongated styloid process in panoramic radiographs in edentulous patients. Turk J Med Sci. 1999; 29(4): 481-486.

6. Correll RW, Jensen JL, Taylor JB, et al. Mineralization of the stylohyoid-stylomandibular ligament complex. A radiographic incidence study. Oral Surg Oral Med Oral Pathol. 1979; 48(4): 286-291, doi: 10.1016/0030-4220(79)90025-2, indexed in Pubmed: 116179

7. Eagle WW. Elongated Styloid Process: Symptoms and Treatment. Arch Otolaryngol Head Neck Surg. 1958; 67(2): 172-176, doi: 10.1001/archotol.1958.00730010178007.

8. Erol B. Radiological assessment of elongated styloid process and ossified stylohyoid ligament. J Marmara Univ Dent Fac. 1996; 2(2-3): 554-556, indexed in Pubmed: 9569816.

9. Farkas LG, Katic MJ, Forrest CR, et al. International anthropometric study of facial morphology in various ethnic groups/races. J Craniofac Surg. 2005; 16(4): 615-646, doi: 10.1097/01.scs.0000171847.58031.9e, indexed in Pubmed: 16077306.

10. Ferrario VF, Sigurtá D, Daddona A, et al. Calcification of the stylohyoid ligament: incidence and morphoquantitative evaluations. Oral Surg Oral Med Oral Pathol. 1990; 69(4): 524-529, doi: 10.1016/0030-4220(90)90390-e, indexed in Pubmed: 2326043.

11. Fusco DJ, Asteraki S, Spetzler RF. Eagle's syndrome: embryology, anatomy, and clinical management. Acta Neurochir (Wien). 2012; 154(7): 1119-1126, doi: 10.1007/s00701012-1385-2, indexed in Pubmed: 22638594.

12. Gokce C, Sisman Y, Ertas ET, et al. Prevalence of styloid process elongation on panoramic radiography in the Turkey population from cappadocia region. Eur J Dent. 2008; 2(1): 18-22, indexed in Pubmed: 19212504.

13. Gossman JR, Tarsitano JJ. The styloid-stylohyoid syndrome. J Oral Surg. 1977; 35(7): 555-560, indexed in Pubmed: 406372.

14. Gözil R, Yener N, Calgüner E, et al. Morphological characteristics of styloid process evaluated by computerized axial tomography. Ann Anat. 2001; 183(6): 527-535, doi: 10.1016/ S0940-9602(01)80060-1, indexed in Pubmed: 11766524.

15. Hosokawa K, Shigematsu H, Oku Y, et al. Extraoral surgical treatment for styloid process syndrome: a case report. Jpn J Oral Maxillofac Surg. 2011; 57(5): 299-303, doi: 10.5794/jjoms.57.299.

16. Ilgüy $M$, Ilgüy $D$, Güler $N$, et al. Incidence of the type and calcification patterns in patients with elongated styloid process. J Int Med Res. 2005; 33(1): 96-102, doi: 10.117 7/147323000503300110, indexed in Pubmed: 15651721.

17. Katayama N, Egawa K, Kashiwagi $H$, et al. The elongated styloid process. Oto-Rhino-Laryngology. 1989; 32(1): 51-58. 
18. Kaufman SM, Elzay RP, Irish EF. Styloid process variation. Radiologic and clinical study. Arch Otolaryngol. 1970; 91(5): 460-463, doi: 10.1001/archotol.1970.00770040654013, indexed in Pubmed: 5442737.

19. Keur JJ, Campbell JP, McCarthy JF, et al. The clinical significance of the elongated styloid process. Oral Surg Oral Med Oral Pathol. 1986; 61(4): 399-404, doi: 10.1016/00304220(86)90426-3, indexed in Pubmed: 3458151.

20. Kitoh R, Takumi Y, Usami S. One case with a giant elongated styloid process surgically resected using the transcervical approach. Stomato-Pharyngology. 2013; 26(1): 105-109.

21. Kumar SS, Kumar TS, et al. Morphometric study of styloid process of the temporal bone and its clinical importance. Int J Anat Res. 2016; 4(1): 2134-2138, doi: 10.16965/ ijar.2016.163.

22. Kursoglu P, Unalan F, Erdem T. Radiological evaluation of the styloid process in young adults resident in Turkey's Yeditepe University faculty of dentistry. Oral Surg Oral Med Oral Pathol Oral Radiol Endod. 2005; 100(4): 491-494, doi: 10.1016/j.tripleo.2005.05.061, indexed in Pubmed: 16182171

23. Langlais $R$, Miles $D$, Van Dis ML. Elongated and mineralized stylohyoid ligament complex: a proposed classification and report of a case of Eagle's syndrome. Oral Surgery, Oral Medicine, Oral Pathology. 1986; 61(5): 527-532, doi: 10.1016/0030-4220(86)90400-7.

24. Margam S, Jadhav S. Morphometric study of styloid process of temporal bone in Indian adult dry skull. Int J Res Med Sci. 2015: 1348-1352, doi: 10.18203/2320-6012. ijrms20150145.

25. Moffat DA, Ramsden RT, Shaw HJ. The styloid process syndrome: aetiological factors and surgical management. J Laryngol Otol. 1977; 91(4): 279-294, doi: 10.1017/ s0022215100083699, indexed in Pubmed: 856922.

26. Monsour PA, Young WG. Variability of the styloid process and stylohyoid ligament in panoramic radiographs. Oral Surg Oral Med Oral Pathol. 1986; 61(5): 522-526, doi: 10.1016/0030-4220(86)90399-3, indexed in Pubmed: 3086788.

27. More $\mathrm{CB}$, Asrani MK. Evaluation of the styloid process on digital panoramic radiographs. Indian J Radiol Imaging. 2010; 20(4): 261-265, doi: 10.4103/0971-3026.73537, indexed in Pubmed: 21423900.

28. Murtagh RD, Caracciolo T, Fernandez GCT. findings associated with Eagle syndrome. AJNR Am J Neuroradiol. 2001; 22(7): 1401-1412.

29. Nakata $M$, Nishio J, Watatani $K$, et al. A radiographic analysis of styloid process. Jpn J Oral Maxillofac Surg. 1987; 33(11): 2224-2229, doi: 10.5794/jjoms. 33.2224.

30. Nara S. Clinical and roentogenological study of abnormal styloid process. J Otolaryngol Jpn. 1958; 61(8): 1295-1301, doi: 10.3950/jibiinkoka.61.1295.

31. Natsis K, Repousi E, Noussios G, et al. The styloid process in a Greek population: an anatomical study with clinical implications. Anat Sci Int. 2015; 90(2): 67-74, doi: 10.1007/ s12565-014-0232-3, indexed in Pubmed: 24664363.

32. Nedunchezhian K. Eagle syndrome: an overview. S Afr J Rad. 2017; 21(1), doi: 10.4102/sajr.v21i1.1247.

33. O'Carroll MK. Calcification in the stylohyoid ligament. Oral Surg Oral Med Oral Pathol. 1984; 58(5): 617-621, doi: 10.1016/0030-4220(84)90089-6.

34. Phulambrikar T, Rajeshwari A, Rao B, et al. Incidence of elongated styloid process: a radiographic study. J Indian Acad Oral Med Radiol. 2011; 23: S344-S346, doi: 10.5005/ jp-journals-10011-1165.
35. Piagkou M, Anagnostopoulou S, Kouladouros K, et al. Eagle's syndrome: a review of the literature. Clin Anat. 2009; 22(5): 545-558, doi: 10.1002/ca.20804, indexed in Pubmed: 19418452.

36. Prabhu LV, Nayak SR, Pai MM, et al. An unusually lengthy styloid process. Singapore Med J. 2007; 48(2): e34-e36, indexed in Pubmed: 17304374.

37. Prasad KC, Kamath MP, Reddy KJ, et al. Elongated styloid process (Eagle's syndrome): a clinical study. J Oral Maxillofac Surg. 2002; 60(2): 171-175, doi: 10.1053/ joms.2002.29814, indexed in Pubmed: 11815916.

38. Pushpalatha K, Bhat D. Bilaterally elongated styloid process: a case report. Int J Sci Stud. 2014; 2(4): 100-102.

39. Rath G, Anand C. Abnormal styloid process in a human skull. Surg Radiol Anat. 1991; 13(3): 227-229, doi: 10.1007/BF01627991, indexed in Pubmed: 1754958.

40. Rizzatti-Barbosa CM, Ribeiro MC, Silva-Concilio LR, et al. Is an elongated stylohyoid process prevalent in the elderly? A radiographic study in a Brazilian population. Gerodontology. 2005; 22(2): 112-115, doi: 10.1111/j.17412358.2005.00046.x, indexed in Pubmed: 15934355.

41. Rogers K, Chang H. Eagle's syndrome: a case report. Columbia Dent Rev. 2007; 11: 12-14.

42. Russell TE. Eagle's syndrome: diagnostic considerations and report of case. J Am Dent Assoc. 1977; 94(3): 548-550, doi: 10.14219/jada.archive.1977.0003, indexed in Pubmed: 264925.

43. Sisman Y, Gokce C, Ertas ET, et al. Investigation of elongated styloid process prevalence in patients with torus palatinus. Clinical Oral Investigations. 2008; 13(3): 269-272, doi: 10.1007/s00784-008-0232-6.

44. Skrzat J, Mróz I, Walocha J, et al. Bilateral ossification of the stylohyoid ligament. Folia Morphol. 2007; 66(3): 203-206, indexed in Pubmed: 17985321.

45. Strauss M, Zohar Y, Laurian N. Elongated styloid process syndrome: intraoral versus external approach for styloid surgery. Laryngoscope. 1985; 95(8): 976-979, indexed in Pubmed: 4021692.

46. Swain S, Jena A, Sahu M, et al. Eagle's syndrome: our experiences in a tertiary care teaching hospital of eastern india. J Head Neck Physicians Surg. 2017; 5(2): 66, doi: 10.4103/jhnps.jhnps_29_17.

47. Takeuchi S, Kishimoto S, Miyashita $H$. The length of the styloid process on the oral panoramic radiograms. Its relationship to the abnormal sensation in the throat. Practica Oto-Rhino-Laryngologica. 1987; 80(1): 133-138, doi: 10.5631/jibirin.80.133.

48. Tsuruta Y, Sato T, Miyahara $H$, et al. Four cases of elongated styloid process: Patients with abnormal feeling in the throat. Practica Oto-Rhino-Laryngologica. 1985; 78(12): 2783-2791, doi: 10.5631/jibirin.78.2783.

49. Vadgaonkar R, Murlimanju BV, Prabhu LV, et al. Morphological study of styloid process of the temporal bone and its clinical implications. Anat Cell Biol. 2015; 48(3): 195-200, doi: 10.5115/acb.2015.48.3.195, indexed in Pubmed: 26417479.

50. Vieira EM, Guedes OA, Morais SD, et al. Prevalence of elongated styloid process in a Central Brazilian population. J Clin Diagn Res. 2015; 9(9): ZC90-ZC92, doi: 10.7860/ JCDR/2015/14599.6567, indexed in Pubmed: 26501021.

51. Yoshihama K, Mikoshiba T, Takei S. Transcervical operative approach of elongated styloid process.. J Jpn Soc Head Neck Surg. 2016; 25(3): 385-388, doi: 10.5106/jjshns.25.385.

52. Zhuang Z, Landsittel D, Benson S, et al. Facial anthropometric differences among gender, ethnicity, and age groups. Ann Occup Hyg. 2010; 54(4): 391-402, doi: 10.1093/ annhyg/meq007, indexed in Pubmed: 20219836. 